\title{
A contribuição da psicologia escolar na prevenção e no enfrentamento do Bullying
}

\author{
Alane Novais Freire \\ Januária Silva Aires
}

\section{Resumo}

Forma de violência escolar que vem ganhando espaço nos noticiários e causando preocupações a pais, educadores e à sociedade como um todo, o bullying é um fenômeno que ocorre de maneira repetitiva e por tempo prolongado, provocando graves danos ao psiquismo dos envolvidos. Cabe à Psicologia Escolar intervir no enfrentamento e prevenção do bullying, adotando medidas específicas em cada realidade onde acontece e tomando o fenômeno como algo que engloba os aspectos sociais, familiares, escolares e individuais. Para isso, é de fundamental importância a presença do psicólogo escolar/educacional dentro da escola.

Palavras-chave: Violência, bullying, Psicologia Escolar.

\section{The contribution of school psychology in the prevention and coping of Bullying}

\begin{abstract}
Bullying is a way of school violence that has been gaining ground on the news and causing concern to parents, educators and society as a whole. It is a phenomenon that has occurred repetitively for a long time, causing serious damage to the psyche of those involved. School Psychology needs intervene in the fight and prevention against bullying. We need adopt specific measures in each situation where it happens and take the phenomenon as something that encompasses the social, family, school and individual environment. Therefore, the presence of school psychologist in schools is of fundamental importance.
\end{abstract}

Keywords: Violence, bullying, School Psychology.

\section{La contribución da psicología escolar en la prevención y en el enfrentamiento del Bullying}

\section{Resumen}

Forma de violencia escolar que gana espacio en los noticieros y causa preocupaciones a padres, educadores y a la sociedad como un todo, el bullying es un fenómeno que ocurre de manera repetitiva y por tiempo prolongado, provocando graves daños al psiquismo de los involucrados. Cabe a la Psicología Escolar participar en la lucha y prevención contra el bullying adoptando medidas específicas en cada realidad donde sucede y entendiendo el fenómeno como algo que engloba aspectos sociales, familiares, escolares e individuales. Para esto es de fundamental importancia la presencia del psicólogo escolar/educacional dentro de la escuela.

Palabras clave: Violencia, bullying, Psicología escolar. 


\section{Introdução}

Nos últimos tempos, uma nova forma de violência escolar vem ganhando espaço nos noticiários de jornais e revistas e causando preocupações aos pais, educadores e a sociedade em geral. Esse tipo de violência, conhecido como fenômeno bullying, não é um acontecimento novo dentro das escolas, ele apenas tomou forma e ganhou nome específico a partir dos anos 80, quando o estudioso norueguês Olweus (1993) definiu como bullying os atos agressivos, antissociais e repetitivos que ocorrem entre estudantes no contexto escolar.

Apesar de o bullying ocorrer no contexto das instituições escolares, ele não é só um problema da escola, mas de toda sociedade, visto ser um fenômeno que gera problemas a longo prazo, causando graves danos ao psiquismo e interferindo negativamente no desenvolvimento cognitivo, emocional e socioeducacional dos envolvidos (Fante, 2008a).

Desse modo, antes de fazer qualquer inferência sobre a sua origem, colocando a culpa no aluno, na escola, na família ou na sociedade, é necessário compreendê-lo como resultante de problemas que estão inseridos em todos esses ambientes e nas relações que ocorrem entre eles, tendo, portanto, uma visão ecológica do fenômeno.

Dessa forma, qualquer tipo de intervenção ao bullying deve levar em consideração as dimensões sociais, educacionais, familiares e individuais, partindo do pressuposto de que elas vão se diferenciar dependendo do contexto em que estão inseridas.

A escola é um contexto que propicia desenvolvimento de habilidades, competências, formação e desenvolvimento de conceitos, saberes e opiniões, por isso tem o papel fundamental de buscar alternativas para o enfrentamento e prevenção do bullying. Nessa perspectiva, aponta-se a importância da inserção do psicólogo escolar/educacional, objetivando realizar um trabalho de prevenção e enfrentamento da violência no contexto em que ocorre.

\section{Fenômeno bullying}

Os estudos sobre bullying se iniciaram na década de 70 na Suécia e na Dinamarca, no entanto esse fenômeno sempre existiu no ambiente escolar, mas não era caracterizado como tal, por se acreditar que não se passava de brincadeiras inofensivas e normais entre os estudantes. Foi na década de 80 que os estudos sobre o tema tomaram proporções maiores devido aos estudos feitos na Noruega por Dan Olweus (Chalita, 2007).

Inicialmente não foi dada muita importância aos estudos de Olweus, porém, em 1983, três meninos noruegueses, na faixa etária entre 10 e 14 anos, cometeram suicídio e a provável causa foram os maus-tratos sofridos na escola. A partir desse acontecimento, Olweus deu continuidade aos seus estudos e organizou suas conclusões no livro Bullying at school: what we know and what we can do (Bullying na escola: o que sabemos e o que podemos fazer), ainda sem tradução para o português. Nesse livro, o autor apresenta o problema, dá sugestões para identificação das vítimas e dos agressores e traça estratégias de prevenção (Chalita, 2007).

O tema chegou ao Brasil no fim dos anos 90 e início de 2000 , e as pesquisas realizadas englobavam apenas a realidade dos locais onde eram realizadas. Mas, na década de 80 , já se realizavam estudos sobre a depredação de prédios escolares e aos poucos os estudos atingiram as relações interpessoais agressivas (Antunes \& Zuin, 2008).

Entende-se por bullying um fenômeno que se refere a ações agressivas e gratuitas contra uma mesma vítima, que ocorrem num período prolongado de tempo e são marcadas pelo desequilíbrio de poder. Ele difere de outros tipos de agressões justamente pelo fato de ser um comportamento repetitivo, deliberado e intencional, não se referindo a divergências de ponto de vista ou de ideias contrárias que provocam desentendimentos e brigas (Fante, 2005, 2008a).

Ressalta-se um ponto importante na caracterização desse fenômeno, a repetição. E acrescenta-se o fato de o mesmo ser de difícil identificação por acontecer longe de adultos e por não haver denúncias por parte das vítimas devido ao medo de retaliação. "A violência, tanto para quem comete quanto para quem é submetida a ela, é, na maioria das vezes, uma questão de violência repetida, tênue e dificilmente perceptível" (Derbabieux, 2002, p. 29).

$\mathrm{O}$ que torna graves os atos de incivilidade, intimidações, assédio ou qualquer outro termo que se queira relacionar ao bullying é exatamente a sua continuidade, que causa às vítimas sensações de abandono e insegurança e aos agressores o sentimento de impunidade e poder (Fante, 2008a).

Esses atos repetitivos e prejudiciais podem ocorrer de várias formas, por isso o bullying pode ser classificado como: direto e indireto. Além disso, nos últimos anos, com o avanço da tecnologia e da internet, outra modalidade começou a surgir, o ciberbullying.

O bullying é classificado como direto quando as vítimas são atacadas diretamente. São considerados bullying direto os apelidos, agressões físicas, ameaças, roubos, ofensas verbais ou expressões e gestos que geram mal estar aos alvos. O bullying indireto são ações que levam exclusivamente ao isolamento social. Este envolve atitudes de indiferença, isolamento, difamação, exclusão (Lopes Neto, 2005).

O ciberbullying se caracteriza pelo uso de e-mails, mensagens de celulares, fotos digitais e sites pessoais difamatórios como recursos para a adoção de comportamentos repetidos e hostis, de um indivíduo ou grupo, que pretende causar danos a outros. Os agressores que utilizam o ciberbullying se motivam pelo anonimato, pois utilizam apenas apelidos ou se fazem passar por outras pessoas (Fante \& Pedra, 2008).

Outro fator que merece destaque nesse tipo de comportamento é a forma rápida como o bullying se espalha, extrapolando os muros da escola. A propagação das difamações é imediata e o efeito multiplicador do sofrimento das vítimas é imensurável (Fante, 2008b). 
Os envolvidos tanto no cyberbullying como no bullying direto ou indireto foram caracterizados pela Associação Brasileira de Proteção à Criança e ao Adolescente (ABRAPIA) como autores, alvos, espectadores e alvos/autores. Essa nova forma de classificação tem o cuidado de não rotular os estudantes, evitando que sejam estigmatizados pela sociedade.

Os autores de bullying são aqueles que praticam as agressões contra os colegas, vitimizando os mais fracos e usando a agressividade para se impor e liderar algum grupo. Costumam humilhar os colegas para serem valorizados socialmente. São geralmente muito habilidosos ao usar esse poder com colegas mais vulneráveis e que não conseguem fazer frente às agressões (Schäfer, 2005).

Consideram-se alvos os alunos que estão expostos de forma repetida, e durante algum tempo, às ações negativas praticadas por um ou mais alunos no ambiente escolar (Antunes \& Zuin, 2008). Eles podem sofrer silenciosamente as agressões, sendo os chamados alvos típicos ou podem agir de maneira impulsiva, provocando ou agredindo outros colegas, esses são denominados alvos provocadores ou agressores.

Os alvos/autores são aqueles alunos que, além de sofrerem agressões, também apresentam um comportamento agressor e provocador. Os espectadores são aqueles que não participam de forma direta das agressões, mas sofrem as consequências das mesmas por presenciarem situações vividas por colegas na escola (Camargo, 2009).

Identificar e diferenciar os envolvidos no fenômeno bullying é uma tarefa difícil devido às peculiaridades que envolvem esse fenômeno. Dessa forma, é preciso estar sempre atento a qualquer mudança no comportamento das crianças e jovens, mesmo que pareça insignificante (Fante, 2005).

\section{Percepções sobre as causas do bullying: uma visão ecológica do fenômeno}

Ainda há muito que ser discutido e avaliado a respeito das causas do fenômeno bullying e das medidas de prevenção e enfrentamento. É comum citarem como causas características de um único ambiente ou dos próprios envolvidos. Alguns estudiosos desse fenômeno chegam a afirmar que o autor de bullying, por exemplo, manifesta esse tipo de comportamento por ser infeliz, ter baixa autoestima e se sentir desvinculado ou impotente em outras áreas da sua vida (Beaudoin, 2007).

Diante disso, formas prontas de enfrentamento do bullying são criadas e levadas às escolas como se todos os contextos onde esse fenômeno ocorre fossem iguais. Muitas vezes essas medidas de enfrentamento colocam o fenômeno como sendo de responsabilidade judicial. São criados projetos de leis, disque denúncias, e a polícia entra na escola como uma forma de intimidação.

É preciso pensar o bullying escolar como um fenômeno social, portanto as formas de enfrentamento e prevenção devem estar em plena comunhão com o contexto onde ocorre, envolvendo medidas psicopedagógicas e preventivas que levem em consideração aspectos sociais, psicológicos e econômicos muito mais do que medidas caracterizadas por punições, ameaças e intimidações ou formas prontas de enfrenatmento.

Por esse motivo é que se pretende pensar o fenômeno da violência escolar, mais especificamente o bullying, a partir de uma visão ecológica. Isso significa se opor às abordagens mais individualistas que entendem esse problema como derivado unicamente de problemas gerados dentro da instituição, seja nas formas de gestão autocrática ou metodologias e avaliações excludentes, na precariedade do ensino ou na falta de interação entre família e escola (Abramoway e cols., 2003, 2005).

A ideia de meio ambiente numa visão ecológica não se limita a um ambiente único ou apenas ao contexto imediato em que o indivíduo está inserido, mas inclui as interconexões entre vários ambientes, bem como as influências que provêm de meios mais amplos. O indivíduo tem papel ativo e interativo nas mudanças que ocorrem no contexto em que está inserido. A interação entre a pessoa e os ambientes é, então, bidirecional, ou seja, da mesma forma que as estruturas ambientais influenciam no desenvolvimento e comportamento do indivíduo, este também pode provocar alterações no seu contexto (Bronfenbrenner, 1996).

É necessário, então, analisar e compreender o ser humano nos diferentes contextos em que ele está inserido, inclusive suas características individuais. Da mesma forma, pode-se pensar no fenômeno bullying. Assim como as características de personalidade e de temperamento, os contextos sociais, familiares e escolares exercem influências no desenvolvimento de comportamentos agressivos entre crianças e jovens.

Para prevenir e enfrentar o bullying ou qualquer outro tipo de violência que ocorre no contexto escolar, não se deve partir de receitas prontas e fechadas, pois cada escola possui uma realidade específica, onde são construídas relações diferenciadas entre os seus membros. Sendo assim, o bullying também irá se apresentar de formas diferentes em cada contexto, não devendo, portanto, ser avaliado de modo descontextualizado.

Diante disso, a atuação do psicólogo escolar/educacional no enfrentamento do bullying deve estar ancorada em uma proposta de caráter preventivo que tenta compreender, analisar e intervir na realidade escolar, considerando a especificidade de cada instituição (Marinho-Araujo \& Almeida, 2008).

\section{A intervenção da Psicologia Escolar/Educacional}

Apesar de a atuação do psicólogo escolar/educacional ter se iniciado com um cunho clínico, na identificação de alunos com distúrbios de aprendizagem, problemas de conduta e de personalidade, atualmente a atuação desse profissional vem tomando novas direções e está cada vez 
mais comprometida com o aspecto social (Del Prette \& Del Prette, 1996).

A atuação do psicólogo escolar/educacional exige a capacidade de analisar e apreender as múltiplas relações que caracterizam a instituição escolar e os agentes nela envolvidos, além de identificar as necessidades e possibilidades de aperfeiçoamento dessas relações. Logo, o profissional de Psicologia deve enfrentar o desafio de tomar como alvo de sua atuação a complexidade dos processos interativos que ocorrem na escola (Del Prette \& Del Prette, 1996).

Por ser a escola uma instituição que reflete a organização social, é imprescindível que se considerem os indivíduos que dela participam a partir de sua inserção no contexto mais amplo da organização. Um trabalho eficiente em Psicologia Escolar/Educacional deve partir da análise da instituição, levando em consideração o meio no qual se encontra, o tipo de demanda que atende e os diversos agentes envolvidos (Andaló, 1984).

O psicólogo é o profissional apto para realizar um trabalho de prevenção e enfrentamento da violência escolar, ajudando a escola a construir espaços e relações mais saudáveis. Mas, para isso, é de fundamental importância que ele esteja inserido no ambiente da escola, participando do seu cotidiano para que possa ter uma atuação específica e mais voltada à realidade.

Será no campo das relações estabelecidas dentro da instituição e desta com o ambiente no qual está inserida que o profissional de Psicologia terá condições de desenvolver novas alternativas para o seu trabalho. O psicólogo deve ocupar um lugar de escuta, possibilitando que se criem espaços de discussões e construção de conhecimento de forma que os problemas sejam discutidos e a busca por soluções seja compartilhada (Martins, 2003).

Estando o psicólogo ligado à instituição, ele tem a possibilidade de atuar como agente de mudanças, capaz de promover reflexões a respeito do tema da violência, podendo, assim, conscientizar os agentes institucionais sobre os seus papéis, garantindo a construção de relações mais saudáveis e evitando o surgimento de qualquer forma de violência nas escolas.

Nessa perspectiva, o profissional de Psicologia deve começar seu trabalho mapeando a instituição, conhecendo como estão sendo estabelecidas as relações, os conflitos existentes e as contradições institucionais que podem propiciar a problemática estudada (Marinho-Araujo \& Almeida, 2008).

A realização do mapeamento permite a esse profissional conhecer a realidade da escola, suas características culturais, sociais e psicológicas, bem como as relações estabelecidas entre os membros da instituição e entre esta, as famílias e a comunidade, possibilitando o conhecimento do panorama geral das relações interpessoais que acontecem dentro e ao redor da instituição (Marinho-Araujo \& Almeida, 2008; Ortega \& Del Rey, 2002).

Conhecendo a realidade da instituição, o psicólogo escolar pode atuar de modo intencional sobre os problemas instalados, bem como sobre o desenvolvimento de habilida- des e competências de toda comunidade escolar, caracterizando uma atuação preventiva e/ou interventiva (Marinho-Araujo \& Almeida, 2008).

Na problemática em questão, uma atuação institucional preventiva deve estar ancorada na promoção de reflexões, conscientizações de papéis e nas funções dos indivíduos, objetivando desenvolver competências e habilidades para a superação de obstáculos e para o estabelecimento de relações sociais mais saudáveis (Marinho-Araujo \& Almeida, 2008).

Devem-se criar espaços de escuta psicológica, a fim de ressignificar as relações interpessoais na escola, conscientizar e transformar práticas existentes que estejam impedindo a consolidação de um ambiente saudável e propício ao aprendizado e ao desenvolvimento dessas relações. Associado a isso, o psicólogo escolar/educacional deve assessorar o trabalho coletivo da escola, instrumentalizando a equipe através de estudos e capacitações, contribuindo na formação dos professores e colocando-os também como coparticipantes nesse trabalho (Marinho-Araujo \& Almeida, 2008).

A atuação junto ao corpo docente e discente, à direção e à equipe técnica contribuirá para que aprendam a resolver seus próprios conflitos do cotidiano de maneira consciente, reflexiva e dialogada, conscientizando a todos sobre a realidade vivida na escola e possibilitando uma melhoria no clima de convivência e no estabelecimento de relações mais saudáveis (Ortega \& Del Rey, 2002).

O psicólogo pode, ainda, promover espaços de discussões e reflexões que possam abordar temas como: uso de estratégias para o desenvolvimento da comunicação, construção de um ambiente de confiança e respeito mútuo, verificação de ambiguidades e conflitos existentes nas relações (Marinho-Araujo \& Almeida, 2008).

Outro tema que deve ser abordado nas escolas com a mediação do psicólogo é a construção de normas e regras institucionais. Nessa perspectiva, o psicólogo irá atingir diretamente as questões relacionadas ao fortalecimento de vínculos nas relações interpessoais, propiciando um espaço para a elaboração de normas e regras na escola.

O psicólogo pode colaborar e participar desse processo de construção de regras no qual os alunos estão incluídos, dando suporte aos professores e gestores e contribuindo na elaboração de regras que não estejam somente relacionadas ao âmbito pedagógico, mas que estejam também voltadas para a organização e fortalecimento das relações entre os alunos, entre os professores e os alunos e entre a escola e a família.

Quando os alunos se tornam ativos nesse processo, a tendência é que eles comecem a assumir essas regras como suas e, consequentemente, passam a se esforçar para cumpri-las (Ortega \& Del Rey, 2002). Além disso, ao perceber que os professores e os gestores estão valorizando suas opiniões, os alunos começam a estabelecer uma relação de respeito não só pelas regras, como também pelas pessoas que participaram desse processo de construção. O cumprimento dessas poderá evitar problemas de indisciplina, de conflitos e do enfraquecimento de vínculos interpessoais. 
Ante o exposto, percebe-se que, muito mais do que medidas prontas e fora da realidade escolar, o enfrentamento e a prevenção do bullying passa por um trabalho inicial de investigação e posteriormente por uma atuação intencional e comprometida com a realidade estudada, daí a importância do profissional de Psicologia nesse contexto.

\section{Considerações finais}

A violência como um fenômeno social, mutável e histórico (Abramoway e cols., 2005) pode ocorrer de diferentes formas dependendo dos contextos social, cultural e econômico, das características dos sujeitos que estão envolvidos e das relações estabelecidas entre eles. Sendo assim, o enfrentamento e a prevenção de qualquer tipo de violência escolar devem partir de uma investigação in loco do fenômeno para que se possa intervir de acordo com cada realidade.

O bullying como um fenômeno social de grande relevância, que possui características específicas, deve ser analisado a partir das peculiaridades de cada contexto, considerando a subjetividade dos envolvidos bem como as características sociais, culturais e econômicas de cada realidade.

Logo, é preciso investigar os fatores que estão levando os estudantes a agirem de forma agressiva, interpretando o fenômeno da violência escolar de modo a compreender os problemas interpessoais e macrossociais, partindo da análise das relações existentes entre os diversos ambientes nos quais os indivíduos estão inseridos (Chiorlin, 2007).

Para isso, é fundamental a presença do psicólogo escolar/educacional na escola, pois ele irá contribuir para o reconhecimento de comportamentos e atitudes que dificultam as relações interpessoais, que geram conflitos e que podem levar ao aparecimento de atos de violência e agressividade entre os alunos.

A partir daí, esse profissional será capaz de avaliar, analisar, refletir e provocar reflexões a respeito das interações sociais e dos conflitos existentes na dinâmica escolar. Desse modo, desenvolverá estratégias próprias de intervenção e prevenção, contribuindo para o desenvolvimento de competências e habilidades de todos os agentes educacionais envolvidos no contexto escolar.

Logo, a inserção do profissional de Psicologia no ambiente escolar seria fundamental não só para trabalhar o desenvolvimento cognitivo, mas também o desenvolvimento emocional e pessoal dos estudantes e profissionais de educação, trazendo trabalhos preventivos com ênfase na cidadania, incentivando a solidariedade, a generosidade, a paz, a tolerância e o respeito às diferenças.

Nessa perspectiva, o psicólogo atuaria na mediação de conhecimentos, valores, normas e atitudes positivas, auxiliando tanto os profissionais quanto os alunos a lidarem com suas emoções, criando espaços para a expressão de afeto e contribuindo para a reflexão e melhoria das relações sociais na escola.

\section{Referências}

Abramoway, M. e cols. (2003). Escolas inovadoras: experiências bem sucedidas em escolas públicas. Brasília: UNESCO.

Abramoway, M. e cols. (2005). Cotidiano das escolas: entre violências. Brasília: UNESCO. Observatório de violência nas escolas. Ministério da Educação.

Andaló, C. S. A. (1984). O papel do psicólogo escolar. Psicologia: Ciência e profissão, 1, 43-47.

Antunes, D. C., \& Zuin, A. A. S. (2008). Do bullying ao preconceito: os desafios da barbárie à educação. Psicologia e Sociedade,20(1), 33-42. Recuperado: 19 jul. 2009.Disponível: http://www. scielo. com.br/scielo.php.

Beaudoin, M. N. (2007). Qual a abordagem mais adequada para lidar com o bullying na escola? Revista Pátio.Ano XI, maio/julho.

Bronfenbrenner, U. (1996). A ecologia do desenvolvimento humano: experimentos naturais e planejados (M. A. V. Veronese, Trad.). Porto Alegre: Artes Médicas (Trabalho original publicado em 1979)

Camargo, C. G. (2009). "Brincadeiras" que fazem chorar: introdução ao fenômeno bullying. São Paulo: All Print.

Chalita, G. (2007). Pedagogia da amizade: bullying - o sofrimento das vítimas e dos agressores. São Paulo: Vozes.

Chiorlin, M. de O.(2007). A influência do bullying no processo de ensino-aprendizagem. São Paulo: Ufscar. Recuperado: 16 set. 2009. Disponível: http://www.ufscar.br/ pedagogia/novo/files

Del Prette, Z. A. P., \& Del Prette, A. (1996). Habilidades envolvidas na atuação do Psicólogo Escolar/Educacional. Em S. M. Wechsler (Org.), Psicologia escolar: pesquisa, formação e prática (pp. 139156). Campinas, SP: Alínea.

Derbabieux, E. (2002). Cientistas, políticos e violência: rumo a uma comunidade científica europeia para lidar com a violência nas escolas? Em E. Debarbieux \& C. Blaya (Orgs.), Violência nas escolas: dez abordagens europeias. Brasília: UNESCO.

Fante, C., \& Pedra, J. A. (2008). Bullying escolar: perguntas e respostas. Porto Alegre: Artmed.

Fante, C. (2008a). Brincadeiras perversas. Viver Mente e Cérebro, ano XV, 181, 74-79.

Fante, C. (2008b). Os danos do ciberbullying. Revista Pátio. Ano XI, $n^{\circ} 44$.

Lopes Neto, A. A. N. (2005). Bullying - comportamento agressivo entre estudantes. Jornal de Pediatria, 81(5), 164 -176. 
Marinho-Araujo, C. M., \& Almeida, S. F. C. de. (2008). Psicologia Escolar: construção e consolidação da identidade profissional (2a ed.). Campinas, SP: Alínea.

Martins, J. B. (2003). A atuação do psicólogo escolar: multirreferencialidade, implicação e escuta clínica. Psicologia em estudo, 8(2), 39-45.

Olweus, D. (1993). Bullying na escola: o que nós sabemos e o que nós podemos fazer. Oxford: Publishers de Oxford Blackwell.
Ortega, R., \& Del Rey, R. (2002). Estratégias educativas para a prevenção da violência (J. Ozório, Trad.). Brasília: UNESCO, UCB.

Schäfer, M. (2005). Abaixo os valentões. Viver Mente e cérebro. Ano XIII, 152, 78-83.

Recebido em:03/03/2011

Reformulado em:13/09/2011

Aprovado em:19/12/2011

\section{Sobre as autoras}

Alane Novais Freire (alanenfreire@gmail.com)

Psicóloga. Formada pela Universidade Federal do Maranhão. Endereço: Rua Álvaro Fernandes Farias, n 197, Bairro Nova Brasília, São Gabriel - BA. CEP: 44915-000

Januária Silva Aires (cefape2001@yahoo.com.br)

Psicóloga. Formada pela Universidade Federal do Maranhão. Mestre em Psicologia. Título de Especialista em Psicopedagogia. Professora Assistente da Universidade Federal do Maranhão. Endereço: Rua 16; Quadra 40; casa 14, Residencial Pinheiros, Cohama São Luís - MA. CEP: $65062-703$ 